\title{
Pronouns and procedures: Reference and beyond
}

\author{
Kate Scott * \\ Department of Linguistics and Languages, Kingston University, Penrhyn Road, Kingston upon Thames, \\ Surrey KT1 2EE, United Kingdom \\ Received 5 March 2015; accepted 16 July 2015
}

\begin{abstract}
In this paper I bring together discussion of two types of meaning that have informed and driven Blakemore's work: procedural meaning and expressive meaning, and I consider how application of Blakemore's influential ideas can further our understanding of pronouns in English. I revisit existing procedural accounts of pronouns, and explore the nature of the procedures that they propose. I argue that if we treat procedural meaning as operating at a sub-personal level, then we gain insight not only into how pronouns function in communication, but also into the nature of procedural meaning itself. The cognitive processes triggered by pronouns reveal the speaker's sub-personal categorization of the intended referents. Often this will guide the hearer in reference resolution, but in certain cases the procedures contribute to other inferential processes. I focus on examples where the pronouns lead to expressive effects, and consider what this tells us, more generally, about the nature of pronouns, procedures and expressive meaning.

(C) 2015 Elsevier B.V. All rights reserved.
\end{abstract}

Keywords: Reference; Pronoun; Expressives; Procedural meaning; Relevance theory

\section{Introduction}

It is generally acknowledged that when a speaker utters a pronoun in English, the content communicated by use of the pronoun will vary from context to context, although a common core of linguistic meaning will remain constant across these different uses. Consider the example in (1):

(1) I gave it to him.

When spoken by Diane in one particular discourse context, the utterance in (1) might be taken to express the proposition in (2). However, when spoken by Becci in a different context, it might express the proposition in (3).

(2) Diane gave the glass to Billy.

(3) Becci gave the book to Tim.

In some sense Diane and Becci have said the same thing. They have, after all, uttered the same words in the same order. However, the propositions that they have expressed are different and have different truth conditions. Kaplan explained

\footnotetext{
* Tel.: +442084172391.

E-mail address: kate.scott@kingston.ac.uk.
} 
this discrepancy by drawing a distinction between content and character (Kaplan, 1989). Diane Blakemore (1987, 1992, $2000,2002,2007$ ) offers an alternative perspective by proposing that some linguistic expressions encode procedures, rather than concepts, and that these procedures guide the process of inferential comprehension. Several procedural analyses of pronouns have been developed; in this article I examine these existing accounts and suggest some developments. I make two main claims. First, I claim that pronouns in English are fully procedural, and that their encoded procedural meaning functions at a sub-personal level. Thus, I move away from accounts that analyse pronouns either as encoding concepts directly, or as encoding features that are analysable in terms of concepts in the language of thought. Rather, I will follow Wilson's (2011:10) characterisation of procedural expressions as being "systematically linked to states of language users". A speaker's choice of pronoun reflects how that speaker sub-personally categorises the intended referent. An important consequence of this approach is that the procedure encoded by a pronoun can contribute not only to reference resolution but to other inferential processes as well. This brings me to my second main claim. I claim that existing accounts overlook the role played by pronouns above and beyond the identification of the proposition expressed. For the purposes of this discussion, I focus on examples where the choice of pronoun is linked to the communication of attitudes and emotions, and by doing so I link the work on procedural meaning to Blakemore's recent work on expressives (Blakemore, 2011, 2014).

In Section 2, I provide a brief overview of the relevance theoretic framework and introduce the idea of procedural meaning. In Section 3, I outline some existing procedural analyses of pronouns. I suggest that while they move us forward in understanding how pronouns function in utterance interpretation, they have various limitations and raise interesting questions about the nature of the procedures themselves. In Section 4, I outline a new approach which treats the procedures encoded by pronouns as operating at a sub-personal level. I will briefly introduce the personal/sub-personal distinction, and discuss how it links to relevance theory generally and procedural meaning specifically. On this approach, the gender, number and person features encoded by pronouns do not pick out personal-level concepts such as MALE or FEMALE which figure in a Fodorian conceptual representation system, or "language of thought" (Fodor, 1975, 2008). Rather, the cognitive processes triggered by pronouns function to constrain potential referents to a sub-personally identifiable set. The features encoded by pronouns function procedurally at this sub-personal level, and while the subpersonal mechanisms which pick out the set of potential referents may involve sub-personal concepts, these may never surface to consciousness or figure as part of the proposition expressed. Finally, in Section 5, I consider examples where the choice of pronoun does not play a role in reference resolution, but contributes to other aspects of the speaker's overall meaning, focusing specifically on the communication of expressive effects.

\section{Relevance, procedures and pronouns}

\subsection{Relevance theory}

Relevance theory (Blakemore, 1992; Carston, 2002a; Clark, 2013; Sperber and Wilson, 1986/95; Wilson and Sperber, 2004,2012 ) takes a cognitive approach to utterance interpretation. According to the first, or cognitive, principle of relevance, human cognition tends to be geared towards the maximisation of relevance. That is, we tend to focus our attention and processing resources on inputs that seem likely to result in cognitive effects. The greater the cognitive effects achieved by processing an input, the greater the relevance of that input. However, whenever cognitive effects are derived, some mental effort is expended. This too affects the relevance of that input. Other things being equal, the less effort required to derive a given set of cognitive effects, the greater the relevance of the input. Therefore, relevance is a function of cognitive effects on the one hand, and processing effort on the other. When the input is an ostensive, communicative act, such as an utterance, the addressee is entitled to expect that the effort they put into processing it will be rewarded with a certain level of relevance. More specifically, they are entitled to presume that the utterance will be optimally relevant. This is summarised in Sperber and Wilson's second, or communicative, principle of relevance, given in (4):

Every act of ostensive communication communicates a presumption of its own optimal relevance (Sperber and Wilson, 1986/95:260).

The definition of optimal relevance (5) sets the upper and lower bounds on what an addressee can expect from an ostensive act of communication:

(5) Presumption of optimal relevance (revised)

a. The ostensive stimulus is relevant enough for it to be worth the addressee's effort to process it.

b. The ostensive stimulus is the most relevant one compatible with the communicator's abilities and preferences.

(Sperber and Wilson, 1986/95:270). 
This definition, along with the presumption that the speaker will be aiming to make her utterance optimally relevant, motivates the relevance theoretic comprehension procedure, given in (6).

The Relevance Theoretic Comprehension Procedure:

a. Follow a path of least effort in deriving cognitive effects: test interpretive hypotheses (reference assignments, disambiguations, implicatures, etc.) in order of accessibility.

b. Stop when your expectations of relevance are satisfied (Sperber and Wilson, 2002:18).

This procedure, according to Sperber and Wilson (2002), is automatically used in interpreting an utterance (or other ostensive stimulus). Given the relevance theoretic comprehension procedure and the definition of relevance, processing effort is a crucial factor in the relevance theoretic framework. Both decoding and inference impose a processing load on the hearer. All other things being equal, the more effort the hearer has to put in to derive the overall intended meaning of an utterance, the less relevant it will be. It is therefore in the interests of a speaker aiming at optimal relevance to avoid putting the hearer to unnecessary effort. Some expressions contribute to relevance by directly guiding inferential processes, and thus reducing the hearer's computational processing load. In Blakemore's terms, such expressions encode not conceptual, but procedural meaning.

\subsection{Relevance and procedural meaning}

While regular content words (cat, book, telephone) encode concepts that figure in conceptual representations, Blakemore $(1987,2002)$ points out that some expressions are better analysed in procedural terms. To illustrate the kind of work standardly claimed to be done by procedurally encoded meaning, consider the examples in (7)-(8):

Clare is a vegetarian.

She doesn't like meat.

The utterances in (7) and (8) could stand in many different inferential relations to one another. However, the speaker has the option of indicating which inferential route the hearer is expected to follow by using the non-truth-conditional discourse connectives so and after all, as in (9) and (10).

Clare is a vegetarian. So she doesn't like meat.

Clare is a vegetarian. After all, she doesn't like meat.

Most linguists and philosophers who have looked at such examples agree that the truth conditions of (9) and (10) (and hence the propositions they express) are the same. Both are true if and only if Clare is a vegetarian and she doesn't like meat. However, the inferences that the hearer is encouraged to draw are constrained by the choice of connective. In (9), the suggested inference is that Clare's dislike of meat is a consequence of her vegetarianism. However, in (10), the inference is that her vegetarianism is in some way a consequence of her dislike of meat. Thus, although it does not contribute conceptual information to the proposition expressed by the utterance, the procedural meaning of the discourse connective clearly has an important influence on the inferential phase of interpretation and the implicatures the hearer is encouraged to derive.

Since the idea of procedural meaning was first developed (Blakemore, 1987), there have been various attempts to characterise the individual procedures encoded by different forms of expression (Blakemore, 2000, 2002; Hall, 2007; Hedley, 2007; Iten, 2005; Wharton, 2003). As Wilson and Sperber (1993:16) point out, this is no easy matter, since "[w]e have direct access neither to grammatical computations nor to the inferential computations used in comprehension". Still, it is now quite widely assumed in relevance theory that personal pronouns can be analysed in procedural terms, so that the pronoun she, for instance, facilitates the retrieval of female (or grammatically feminine) candidate referents (see Wilson and Wharton, 2006). In the next section, I briefly consider some existing procedural analyses of pronouns and consider the characterisation of procedures proposed by each account. While offering insight into the role of pronouns in reference resolution, these approaches maintain a personal-level conceptual link between the features carried by the pronouns and the selection of the intended referent. This, I will suggest is limiting in terms of accounting for the full range of effects that may be achieved via the speaker's choice of pronoun. If, instead, we follow the relevance-based assumption that computations, including reference resolution, take place at a subpersonal level, we are able to account for a wider range of examples (Blakemore, 2002; Carston, 2002b; Sperber and Wilson, 1986/95; Wilson, 2011). 


\section{Pronouns and procedures: existing accounts}

\subsection{Introduction}

Consider a simple sentence containing a pronoun, such as (11):

She has a big nose.

The utterance in (11) will be true in just those cases where the person referred to by the pronoun she has a big nose. In order to evaluate the truth of this utterance we need to know who she refers to. It is not the pronoun itself that appears in the proposition expressed but the referent of the pronoun. As Hedley (2005:44) puts it, "their meaning is computational, not representational". In Blakemore's terms, they are procedural.

\subsection{Existing approaches}

Both Ariel (1988, 1990, 1991, 1994, 2001) and Gundel and colleagues (Gundel, 2003, 2010; Gundel et al., 1993; Gundel and Mulkern, 1998) offer scalar accounts of referring expressions, including pronouns. Both present their approaches as procedural in nature and compatible with relevance theory. According to Ariel (2001:29), Accessibility theory "offers a procedural analysis of referring expressions, as marking varying degrees of mental accessibility", and on the Accessibility scale, pronouns mark high accessibility. Similarly, for Gundel (2010:159), referring expressions sit on a "Givenness hierarchy" and "provide procedural information about manner of accessibility". They indicate that the intended referent is either "in focus" (for unstressed pronouns) or "activated" (for stressed pronouns).

I suggest that relying on theory external scales of cognitive activation has two main limitations. First, according to Accessibility theory and the Givenness hierarchy, each referring expression type conventionally (i.e. linguistically) encodes information about the accessibility or cognitive status of the intended referent. This information then guides the hearer in finding the intended referent amongst the potential referents in the discourse context. For Ariel, referring expressions are "guidelines for retrievals" (Ariel, 1988:68) and for Gundel they "conventionally signal different cognitive statuses" (Gundel et al., 1993:274). In both cases, it is therefore possible for the speaker's choice of referring expression to direct the hearer to an entity with low accessibility or low cognitive status in preference to higher ones. Ariel (1994:20) clearly states that "since speakers may wish to refer not to the most salient potential referent, they should overtly instruct the addressee to search for a less salient antecedent". I want to suggest that such overt instruction relating to the activation level of the intended referent is not necessary if we take seriously the role played by the relevance theoretic comprehension procedure, as given in (6). A hearer following the comprehension procedure will always test potential referents in order of accessibility. However, he will only accept the first interpretation as the intended one if it satisfies his expectations of optimal relevance: that is, if it leads to an interpretation on which the utterance is both relevant enough to be worth processing and the most relevant utterance compatible with the speaker's abilities and preferences. Consider the examples in (12) and (13):

John walked into the room. He sat down.

John walked into the room. The man sat down.

When interpreting the subject of the second sentence, John is the most accessible candidate referent in the discourse context in both (12) and (13), and so he will be tested first. In (12), an interpretation on which he is co-referential with John satisfies both clauses of the definition of optimal relevance and so will be accepted. However, in utterance (13), the speaker has chosen to use a definite description rather than a pronoun. This puts the hearer to more processing effort, and can only be justified if it leads to more or different cognitive effects than would have been achieved by use of he. As Wilson explains, an utterance "cannot be optimally relevant if some other utterance that would have been equally easy for the speaker to produce would manifestly have achieved the intended effects more economically" (Wilson, 1992: 179-180). The utterance in (12) would manifestly have done so, had the speaker intended to refer to John. To maintain the presumption that the speaker was aiming at optimal relevance, the hearer of (13) must seek out extra or different effects from those that would have been achieved by use of (12), and so he will reject this interpretation and continue down the path of least effort looking for another possible referent. Thus, the interpretations fall out from general considerations of relevance, and there is no need for specific activation levels to be encoded within the form of referring expression. While I agree with Gundel et al. (1993) that choice of referring expression can be used to restrict the set of potential referents, I suggest that they only do so to a point where general considerations of relevance can take over. If a hearer tests interpretations in order of accessibility and stops only when his expectations of relevance are satisfied, there is no need for the hearer to conventionally signal cognitive activation levels as well. 
A second limitation stems from the way in which the referring expressions are categorised and associated with the points on the respective scales. In both frameworks a distinction is made between stressed and unstressed pronouns, but very little is said about the difference between different unstressed pronouns. According to Accessibility theory all unstressed pronouns signal high accessibility, and on the Givenness hierarchy they signal that the referent is in focus.

Consider the examples in (14) and (15):

(14) Pierre said to Natasha that he should go.

(15) Pierre said to Natasha that she should go.

The only difference between (14) and (15) is the gender of the third person pronoun, and yet the interpretations are very different. In (14), Pierre is telling Natasha that it is Pierre (or some other highly salient male) who should go, whereas in (15), Pierre is telling Natasha that Natasha (or some other highly salient female) should go. The sets of potential referents from which the hearer will resolve reference are mutually exclusive in these two examples, and yet approaches based on scales of accessibilty or givenness do not explicitly discuss how person, number and gender features interact with the assumed procedural meaning relating to cognitive status or accessibility.

There are two possible courses of action that we could take to address this second limitation. Either the procedural meaning encoded by the pronoun is more fine-grained than just that associated with a general category of referring expression, or pronouns encode conceptual information relating to gender (and number and person) alongside the procedurally encoded meaning.

Some recent relevance-theoretic accounts take the second option and propose mixed analyses on which pronouns are seen as encoding both conceptual and procedural information. As Wilson (2011) points out, there is no theoretical reason why an expression cannot encode both conceptual and procedural meaning.

Borthen and Bröseth (2010) and Borthen and Thomassen (2014) follow Gundel et al. (1993) in assuming that pronouns encode procedural information relating to the cognitive status of the intended referent. In their analysis of they, Borthen and Bröseth (2010) also treat person information as procedural, but propose that number and gender features should be treated as conceptual. They argue that "number is not a procedural feature" because "[p]lurality is a piece of meaning which we are perfectly capable of bringing to consciousness" (2010:94) and which can be expressed by a content word such as plurality. However, as discussed above, and as they acknowledge, it is the referent itself and not the plurality feature which forms part of the proposition expressed. They reconcile these two assumptions by suggesting that the conceptual features of the pronoun do not feature as part of the proposition expressed, but instead trigger higher-level explicatures. A typical case of conceptual meaning contributing to higher-level explicatures that is discussed in the relevance theory literature is that of discourse adverbials, such as seriously in (16).

$$
\text { Seriously, Arnold won't get the job. }
$$

According to Carston (2002a:121), discourse adverbials "decode into a mentally represented concept, which must feature in some representation derived by the hearer". In the case of (16), the propositional form of the utterance will be embedded under a higher-level description in which the discourse adverbial modifies the speech-act verb, as in (17).

I tell you seriously that Arnold won't get the job.

According to Borthen and Bröseth (2010), the use of the third person plural pronoun they triggers the higher-level explicatures in (18) and (19):

(18) The speaker describes the referent as being made up of more than one member of a set.

(19) The speaker believes the referent to be made up of more than one member of a set.

However, it is not always the case that use of they entails that the speaker intends to communicate that she believes or describes the referent as being made up of more than one member of a set. In English, they can be and frequently is used to refer to a single person in cases where the gender of that person is not known, as in (20), or in cases where the speaker does not wish to disclose the gender, as in (21).

I'll give this to whomever wins, and they can keep it.

I met a work colleague for a drink, and they persuaded me to stay out late. 
There is no sense in which the speakers of (20) or (21) explicitly communicate that they believe the referents of they are necessarily plural.

Furthermore, as Borthen and Bröseth acknowledge, derivation of higher-level explicatures, such as (18) and (19), would require a revision of the definition of higher-level explicatures along lines suggested in Borthen (2008). In this respect they treat the gender and number features of pronouns as similar to the conceptual content of a definite description such as the liar in (22), which, on this approach, would result in the higher-level explicature in (23) (Borthen, 2008:75):

\section{That liar told Mary he was tired.}

The speaker describes the referent as a liar.

On my alternative approach, I suggest that we can accommodate Borthen and Bröseth's intuition that plurality is in some sense conceptual, while avoiding unnecessary and otherwise unmotivated amendments to the definition of higher-level explicatures. This is possible if we allow that procedural meaning functions at a sub-personal level, and that sub-personal mechanisms may involve internalised concepts or category labels which may never surface to consciousness or figure as part of the proposition expressed by the utterance. Unlike the discourse adverbials discussed by Carston, they do not need to feature in some personal-level representation derived by the hearer as they are not mentally represented at this level.

\subsection{Hedley: towards a procedural account}

Hedley (2005) proposes an account of pronouns which is broadly compatible with relevance theory, and which does not rely on any theory external machinery. For Hedley, a pronoun is:

a linguistic device that can be used by a speaker in order to aid the process of reference resolution for his hearer, while not expending too much time and energy in producing fully specific (and probably repetitive) descriptive noun phrases (2005:7).

On his account, the procedure encoded by I might look something like, "find an individual concept of the speaker" (2005:6), while for singular you, it might be "something along the lines of 'find an individual concept of the hearer"' (2005:8). Hedley explicitly distinguishes between $h e$ and she via the procedures that they encode. He suggests that he encodes a procedure which is something like, "find an individual concept with the feature 'male"' (2005:9), and for she the hearer is instructed to find an individual concept with the feature 'female'. On Hedley's account, it is natural to see the gender information encoded by the pronouns he and she as conceptual in nature, and so it might be tempting to view his approach as another mixed conceptual/procedural analysis. The properties of being male or female are, after all, fairly concrete, and could be represented by the concepts MALE or FEMALE in a Fodorian conceptual representation system, or "language of thought" (Fodor, 1975, 2008). This would in turn suggest that the encoded meanings of pronouns should be seen as at least partly conceptual in nature.

However, as Hedley argues, it is not the concept MALE that enters into the explicature of the utterance, but a representation of the referent itself. As evidence for this claim, he cites Powell's $(2002,2010)$ discussion of the case of Dr James Barry. Dr Barry was an eminent physician who died in 1865 and was discovered, after death, to have been a woman. Compare utterances (24) and (25) as examples of how this situation might be described.

You know, when he was laid out for his funeral it turned out he was really a woman.

?You know, when she was laid out for her funeral it turned out she was really a woman. (Powell, 2010:113)

If the hearer of these utterances believes that $\mathrm{Dr}$ James Barry is a male, then use of the masculine pronoun is the most efficient way to ensure that reference is resolved correctly. Using the feminine pronoun in this discourse context would instruct the hearer to find an individual concept with the feature 'female', and at the stage in the utterance at which reference resolution should take place, Dr James Barry would not (as far as the hearer is concerned) fall into that category. Thus, Hedley treats the pronoun he as encoding a procedure that instructs the hearer to resolve reference on an individual concept with the feature 'male'. He specifies that this feature is "pragmatic in nature (in English) rather than being categorical or semantic" (Hedley, 2005:9 fn.14), and he later elaborates on this:

Procedural indications like 'male', 'speaker', 'plural' etc. in English all operate at the level of evidence provided by the speaker for his hearer... rather than as semantically constraining factors (Hedley, 2007:91).

Thus, Hedley moves away from an analysis where pronouns themselves encode specific conceptual information about inherent features of the referent. Rather, he treats pronouns as encoding pro-concepts: placeholders for concepts which must then be worked out contextually in determining the explicit content of the utterance. 
Like the Accessibility and Givenness-based approaches, Hedley's analysis focuses on the contribution that choice of referring expression makes to the proposition expressed. Whilst I follow him in holding that the work done by pronouns is procedural rather than conceptual or a mixture of both, I suggest that the analysis is taken one step further in order to incorporate the other contributions, including expressive effects, that a pronoun may make. By treating pronouns as encoding procedures that operate at a sub-personal level, an account emerges on which the procedures guide the hearer's inferential processes, without invoking personal-level concepts such as MALE or FEMALE at all. While subpersonal mechanisms and computations may involve internal concepts, these do not figure as part of the proposition expressed or higher level-explicatures. In the next section I introduce the personal/sub-personal distinction and discuss how it might shed light on the contribution that pronominal features might make to reference resolution and utterance interpretation more generally.

\section{Pronominal procedures as sub-personal}

\subsection{The personal/sub-personal distinction}

Relevance theory takes a cognitive approach to utterance interpretation and therefore deals with cognitive processes (Carston, 1999; Wilson, 2011). As Blakemore (2011:3540) points out, relevance theorists are typically concerned with "subpersonal explanations rather than personal explanations". Dennett (1969) was the first to distinguish between psychological explanations that function at a personal level and those that function at a sub-personal level. Personal level explanations function on the assumption that we are conscious, reflective agents, and they explain behaviours in terms of beliefs and desires attributed to such agents. For example, if John is travelling on a London bus and presses the bell, we might interpret this action in terms of his personal beliefs and intentions. John believed that by pressing the bell he would make the driver understand that one of the passengers wanted to disembark at the next stop. John hoped that the driver would stop the bus as a consequence of this. Sub-personal explanations, on the other hand, deal in "entities and properties that can be shown to play a causal role in ... action or behaviour, without necessarily standing in rational or normative relations to it" (Carston, 2002b:131). Dennett illustrates this by considering how we might understand the experience of feeling pain. If we touch a surface and find it to be hot, we will pull our hands away without being able to say that we decided or intended to do so. As Dennett goes on to argue, we cannot describe or explain the sensation of pain that we felt, other than to say that it was painful. We cannot offer a list of criteria which make something painful, or provide a definition for the sensation. Rather, the "only distinguishing characteristic is painfulness, an unanalysable quality that can only be defined circularly" (Dennett, 1969: 91-92). We are, however, all able to recognise the experience of feeling pain, and the claim is that the processes by which we recognise and respond to it operate at a sub-personal level. Procedural meaning also functions at a sub-personal level. While pain may be hard to define as a sensation, we can consciously entertain it as a concept. We are able to think, "I'm in pain" or "That was painful". This seems to be the case with conceptually encoded content. However, it seems to be much more difficult to consciously entertain procedures. It is hard, for example, to put one's finger on what precisely but means, or how it differs from howeveror nevertheless. A competent speaker knows how to use each term correctly, and recognises when they have been used inappropriately, but explaining how or why this is, in personal terms, is much more difficult, and leads to much debate and disagreement (as the ever growing literature on the meanings of discourse connectives confirms). This is characteristic of sub-personal explanations. As Wilson (2011:11) puts it, "domain-specific cognitive procedures are generally seen as formulated in a sub-personal 'machine language' distinct from the language of thought".

\subsection{A sub-personal procedure}

As discussed in Section 3.3, Hedley's procedural account of pronouns relies on features relating to gender, number and person associated with each particular pronoun. The procedures that he suggests (for example, "find an individual concept with the feature 'male"' (2005:9)) seem to rely on a personal level explanation, involving personal-level concepts, such as MALE. I suggest that we gain deeper insight into the role and function of pronouns by seeking an explanation at the sub-personal level instead. On this approach, pronouns contribute to relevance by constraining the set of potential referents to just those which fall into a sub-personally identifiable category. The computations that take place at this subpersonal level, including picking out a set of potential referents for a pronoun, may make use of sub-personal concepts or category labels. However, these may never surface to consciousness or figure as part of the proposition expressed by an utterance. Applying Carston's (2002b:131) definition of a sub-personal explanation, they may "play a causal role" in reference resolution "without necessarily standing in rational or normative relations to it". Taking this approach, will, I suggest, remove some of the limitations inherent in a personal-level approach, and provide insight into a wider range of examples.

The speaker's choice of, for example, a masculine pronoun in preference to a feminine pronoun (or vice versa) does not in general take place at a personal level, using concepts drawn from the vocabulary of the language of thought. It is not necessary for a speaker to check whether the intended referent falls under the personal level concept MALE. Rather, the 
cognitive process triggered by the pronoun constrains the set of potential referents to just those belonging to a category of items that are identifiable in sub-personal rather than personal terms. The ability to identify items belonging to this same category must play a role not only in comprehension, but also in language production: it is just the category of items for which that particular pronoun can be legitimately used.

On the approach I propose, then, the masculine pronoun he encodes a procedure which restricts the set of potential referents to just those belonging to a category identifiable in sub-personal terms as containing items that can be legitimately referred to using the pronoun $h e$. Speakers might be seen as having, as part of their knowledge of the word he, a detector for items which fall into this category. Typically, detectors operate on the basis of cues which pick out stereotypical or prototypical members of a category, but these cues do not amount to a definition. A parallel might be drawn with the pain detector discussed above, or with the visual systems of frogs. According to Lettvin et al. (1959), the frog's fly detector is based on the ability to pick out small black moving dots, and so does not pick out all and only flies. ${ }^{1}$ Having restricted the set in this way, reference resolution proceeds, with potential referents from this sub-personally identifiable category being tested in order of accessibility.

This move away from personal level concepts makes it easy to account for the Dr James Barry type cases, and also sheds interesting new light on other seemingly exceptional examples. Whilst we might make the broad generalisation that the he/she/it distinction in English correlates with the distinction between human males, human females and inanimate objects respectively, there are many less clear-cut cases. A ship (or car, or country), for example, may be referred to as it or she. In my framework, this is simply because it is identifiable in sub-personal terms as belonging both to the set of things that can be referred to as it and the set of things that can be referred to as she. ${ }^{2} \mathrm{~A}$ similar explanation can be given for the otherwise messy issue of how to refer to animals using a pronominal form. A cat or dog may be referred to as he, she or it because it may belong to all three sub-personally identifiable sets, and not because of the natural gender (if known) of the animal itself. Membership of a certain set is therefore dependent on how the particular speaker categorises the particular animal (or how they assume their hearer categorises it), and whilst this may be influenced by natural gender, it is far from determined by it. Gender sets may overlap, and their membership may vary as the discourse context, including the speaker's assumptions and communicative intentions, varies.

Animals may belong to the set of things that can be referred to using the pronoun it, as in (26), but this is not usually the case with humans, even if the gender of the referent is unknown, as in (27).

I'm going to buy [a dog $]_{i}$ and call it $t_{i}$ Spot.

*l'll give this to [whomever wins $]_{j}$ and $i_{j}$ can keep it.

An exception seems to be the case of unborn babies, where in certain circumstances it is just as acceptable as they.

If I ever have a baby, it's going to have the best of everything.

If I ever have a baby, they're going to have the best of everything.

Until the natural gender of the baby is known, it will belong to the set of things that can be referred to using it, as in (28) or they, as in (29). Again we can understand this as a reflection of how the speaker categorises an unborn child, rather than of the child's falling under one or other full-fledged concept.

In summary, I have argued that pronouns are fully procedural. The encoded procedures operate at a sub-personal level to trigger cognitive processes which constrain the set of potential referents and thus guide reference resolution. In the next section I consider some of the consequences and implications of taking such an approach. I argue that a subpersonal approach has several advantages. In particular I suggest that it offers insight into cases where the pronoun contributes more to the overall interpretation than simply guiding the hearer to a referent.

\section{Pronouns and sub-personal procedures}

\subsection{Beyond reference: expressive meaning}

When considering the contribution that pronouns make to utterance interpretation, the existing accounts focus only on the effect that the pronoun might have on derivation of the proposition expressed. For example, Hedley's (2005) proposed

\footnotetext{
${ }^{1}$ Also see Agar (1993) for further discussion.

2 There may be individual differences in how acceptable different speakers find these two possibilities, and this further supports the subpersonal procedural analysis. If it is becoming less common to refer to ships as she (rather than it), we can see this as a change in the subpersonal categorization rather than as a result of ships being less feminine in any full-fledged conceptual sense.
} 
procedure assumes that inferential processes encoded by a pronoun relate only to reference resolution. I want to challenge this assumption on two counts. First, there are cases where the information encoded by the pronoun is redundant in terms of reference resolution, and second, there are cases where a speaker deliberately uses a nonstandard pronoun, and in doing so communicates her attitudes or emotions towards the referent.

First, consider utterance (30).

I spoke to Andrey and he said that all was well.

If we assume that the hearer will test potential referents in order of accessibility, then any specific information associated with the masculine pronoun appears to be redundant in this case. In the discourse context, there are two explicitly mentioned, and therefore highly accessible, potential referents: the speaker of the utterance and Andrey. Removing the pronoun entirely yields a reading where the speaker is the understood subject of the verb said, as in (31). ${ }^{3}$

I spoke to Andrey and said that all was well.

By contrast, utterance (30) leads to an interpretation where reference is resolved on Andrey. It therefore seems reasonable to assume that the speaker is the most accessible potential referent in the discourse context, and that use of the pronoun in (30) eliminates the speaker as a potential referent, leaving Andrey as the first to be tested. Thus, the use of a third person pronoun narrows the hypothesis space for the inferential process of reference resolution. However, on this account, the fact that Andrey belongs to the set of things that can be appropriately referred to by he (as opposed to she) is irrelevant for purposes of reference resolution. The grammar of English forces the speaker to use an appropriately gendered version of the third-person pronoun. However, what is significant in this case is not the encoded gender information but the fact that a third person pronoun has been used.

Second, if choice of pronoun only ever related to reference resolution, we would expect speakers to only ever use a pronoun appropriate to the (perceived) gender of the intended referent. While examples such as (24) (Dr James Barry) may be superficially problematic, once we allow that the speaker is a sophisticated understander in the sense of Sperber (1994), they cease to cause a problem. Speakers, after all, allow for the fact that their hearer may hold a false belief. They can construct a referring expression in such a way that it picks out the intended referent, and thereby contributes to an utterance which contradicts that false assumption. In essence, the speaker of (24) is choosing the most appropriate referring expression to pick out the intended referent, given the hearer's likely assumptions about a person named James Barry. However, there are other cases in which both speaker and hearer are taken to share the same assumptions about the natural gender of the referent, and yet a perhaps unexpected pronoun is used felicitously. In these cases, I will argue that the procedure encoded by the pronoun contributes to relevance, not by the contribution it makes to the proposition expressed, but by the contribution it makes to other parts of the overall intended message.

Consider the following exchange from Drag Queens of London (2014) in which two performers discuss a colleague:

Vicki: Is Baga turning up to rehearsals?

Silver: She's missed a couple of things.

Vicki: As a person I think he's great. . .but professionally I wouldn't go near him. I wouldn't work with him.

Both speakers are referring to the same person throughout the exchange. Silver initially uses she, indicating that she considers Baga to be amongst the set of things appropriately referred to by the feminine first person pronoun despite being aware that Baga is biologically male. However, Vicki uses the pronoun he, and in doing so reveals that she is referring, not to the female stage persona, but to the characteristics of Baga as a male professional performer. The propositions expressed by the utterances are not affected by the switch in pronoun in that both pick out the same person in the world. However, for Silver, Baga is presented as being a member of the set of things that are appropriately referred to as she, while, for Vicki, Baga is presented as being a member of the set of things that are appropriately referred to as he. Choice of pronoun allows the speaker to indicate that a particular aspect of the referent's persona is relevant in the discourse context, based on sub-personally identifiable group membership. This captures the same communicative intention that Borthen and Bröseth categorised as a higher-level explicature ("The speaker describes the referent as a male/female"), without committing to this information being part of the explicitly communicated meaning, or requiring an amendment to the definition of higher-level explicatures.

\footnotetext{
${ }^{3}$ See Matsui (2000) for discussion of possible factors that might contribute to this interpretation, including order of mention, syntactic position and parallel function.
} 
A further, more unusual example is found in the movie The Silence of the Lambs, and given in (33).

$$
\text { It rubs the lotion on its skin. It does this whenever it's told (Demme, 1991). }
$$

This is spoken by serial killer Buffalo Bill to a woman he is holding hostage, and in the context of the scene is intended as an order or command. It is clear to both the female character and the audience that he intends it to refer to his hostage, and that he is describing what he expects her to do to herself. I want to argue that, as with examples (30) and (32), the specific choice of pronoun in (33) has little or no effect on reference resolution. However, the marked use of the pronoun leads to extra expressive effects. This is expected on a relevance approach where marked utterances cost the hearer more effort, which should automatically lead to a search for more effects.

If the speaker simply wanted to order the hearer to do something, the most usual, unmarked, and least effortful way to do so would be to utter (34):

$$
\text { Rub the lotion on your skin. Do this whenever you're told. }
$$

The utterance chosen by Buffalo Bill differs from this in various ways, each of which plays a part in the overall interpretation of the utterance in context. When ordering someone to do something, it is usual to address that person directly. Furthermore, when referring to the addressee in an utterance, it is usual to use the pronoun you. This would be the unmarked option in this case. By using you, the speaker would be indicating that the referent is amongst the set of things that the hearer might expect to be referred to by you. In most cases this will be your partner in the conversation, your interlocutor, the person to whom the utterance is addressed. However, by choosing to use a third person pronoun instead, Buffalo Bill indicates that the hostage is not to be represented as included in this set. That is, the addressee is not to be represented as a conversational partner for him.

However, this is not the only way in which Buffalo Bill distances himself from his addressee. His utterance in (33) takes the disconnection between them one step further. The usual, unmarked way to refer to a female human in $3 \mathrm{rd}$ person is to use the pronoun she, and so Bill could have uttered (35):

She rubs the lotion on her skin. She does this whenever she's told.

On the sub-personal approach, this would indicate to the hearer that the speaker considers the referent to be amongst the set of things that can be referred to by she, placing her in a group with other human females. By choosing to use it instead, Bill reveals that he categorises the hostage as being amongst the set of things that can be referred to by the pronoun it, instead. This would typically include inanimate objects and perhaps animals. In this way he reveals that he does not consider her to be human, but rather an object, animal or commodity.

Finally, Buffalo Bill issues his order using a declarative, rather than the more standard imperative. This in itself is not unusual. We might for example use a declarative to order someone to arrive on time for a lecture, as in (36).

You will arrive on time tomorrow.

However, traditionally, the subjects of imperative sentences have been analysed as second person (Bullokar, 1586; Jespersen, 1940; Sweet, 1960; Katz and Postal, 1964; Thorne, 1966; Schmerling, 1982), and if this is the case, then Buffalo Bill would be using an utterance that directly addressed his hearer. To communicate the same proposition, the possessive pronoun would have to agree with the unarticulated imperative subject, as in (34). As we have seen, he does not view his victim as a human being, and so it is not appropriate to issue her with an order in this form. ${ }^{4}$

The utterance in (33) is more costly for the hearers (both the hostage herself, and the movie audience) to process than the unmarked, expected version in (34). According to relevance theory, this extra effort will be justified if it is either intended to result in more cognitive effects, or can be put down to issues of speaker ability or preference. These justifications may combine if communication of the speaker's abilities or preferences itself is relevant for the hearer. Consider the exchange in (37):

A: Did John get the job?

B: He didn't look happy.

\footnotetext{
${ }^{4}$ After all, we do not usually address imperatives to inanimate objects, and when we do, we temporarily assign them membership of the class of animate objects by referring to them as you. For example, if my key sticks in the door, I might utter "Open, damn you!" 
B's reply does not directly answer A's question, and in that respect may be considered under-informative. However, speaker $B$ can only be as relevant as allowed by her abilities and preferences. A will therefore assume that $B$ is unable or unwilling to be any more specific, and will conclude that $B$ either does not know for sure whether John got the job or does not want to tell A directly. A similar pattern plays out in (33). By using a non-standard pronoun to refer to a female human, the speaker reveals that he does not consider the referent to be amongst the set of things that are usually referred to by she. The hearer may condone this as due to some idiosyncrasy in the speaker's abilities and preferences, but the choice of words may also be intentionally used to reveal something about Buffalo Bill's emotions and attitudes. In that case, the choice of pronoun leads to expressive effects.

In this respect, the choice of a pronoun can function in the same way as the expressive epithets discussed by Blakemore $(2011,2014)$ in examples such as $(38)$ :

I've just been to see Darren. The bastard is going to fire at least 10 members of staff.

Just as the specific choice of pronoun in example (30) does not directly contribute to reference resolution, so the conceptual content in the definite description the bastard does not narrow the set of potential referents to just bastards. As Blakemore (2014:8) notes, in such examples, the DPs "do not have conceptual content which plays a role in the recovery of a reference and hence function more like anaphors". In fact, we could replace the epithet in (38) with a pronoun, as in (39), and the propositional content would be the same:

I've just been to see Darren. He is going to fire at least 10 members of staff.

The utterances in (38) and (39) differ in their expressive effects. This parallels the situation in example (33). The hostage is the most accessible, and only, potential referent in the discourse context, and so will be tested first. The procedural guidelines encoded by the pronoun are not needed in this case. In fact, if the hearer took them to be relevant to reference resolution, she would look for something other than herself on which to resolve reference. There is nothing else with skin in the discourse context, and so this interpretation strategy would fail. Rather, she reconciles the intended interpretation with the speaker's choice of pronoun by assuming that he considers her to be amongst the set of things appropriately referred to by it, rather than she. The use of expressive epithets like the bastard makes certain assumptions accessible, and the relevance of the utterance lies in "the route they provide to the emotions or attitude that the speaker is communicating" (Blakemore, 2013:29). ${ }^{5}$ The same applies with expressive uses of pronouns. However, in these cases the route to the emotions or attitudes involves a procedure and assumptions about the speaker's sub-personal categorization of the referent, rather than a concept.

While the example in (33) is exceptional and extreme in the attitudes and emotions that the speaker expresses, there are also more everyday examples in which a speaker might use it rather than she or he to create a dehumanising or distancing effect. To refer to a baby as it is to associate that baby with inanimate objects or animals, rather than with human beings. In the following exchange, the father of the child, Neil, understands that Luisa is asking what his child is called, but constructs his answer so that the association between the child and the set of things referred to as it is replaced by an association with the set of things that can be appropriately referred to as she.

Luisa: You've got a kid? What's it called?

Neil: She's called Gwyneth. ${ }^{6}$

However, if a crying baby is disturbing a carriage full of passengers on a train, it would usually be acceptable to utter (41) to your companion. In this discourse context, you are only presenting the baby as a noise-producing machine, and the fact that it is a human being is of little or no relevance.

I wish it would shut up.

On his podcast 'Savage Lovecast' Dan Savage (2014) discusses the language used to refer to transgender people. He says "I've heard shock-jocks and bigots and bashers dehumanise trans-people by calling them it", and goes on to say that it is "anti-trans hate-speech to call a trans-person it". The strength of feeling towards the act of referring to a person as it in these circumstances is clear and has been compared with racial and homophobic slurs. ${ }^{7}$

\footnotetext{
${ }^{5}$ This quotation is from a paper presented by Diane Blakemore at the University of Brighton in 2013. A shortened version was published as Blakemore (2014).

${ }^{6}$ With thanks to Neil Smith-Willis and Luisa Gottardo for allowing me to use this overheard example.

${ }^{7}$ With thanks to Sam Wood for the example.
} 
Pronouns, as referring expressions, are not exceptional in the fact that their procedural content can contribute to different aspects of the speaker's intended meaning. In Scott (2013), I examine uses of the demonstrative determiners this and that, and consider how they can be used to communicate information about the speaker's emotions or attitudes. As with some of the uses of pronouns discussed here, there are examples where the choice of demonstrative determiner does not play any direct role in reference resolution, and substitution with the definite determiner, the, would lead to the same explicit meaning. Consider, for example, the utterance in (42):

\section{Doctor to patient: How's that throat?}

The use of that is not needed to guide the hearer to the identification of the intended throat, and substitution with the or your would likely lead to the hearer deriving the same proposition expressed. However, use of a demonstrative encourages the hearer to represent the intended referent as non-unique and this in turn evokes an implicit contrast. Following Neale (2007:103), the use of "that throat" "draws attention to the fact that not any old [throat] will do", and the speaker thus "communicates that she considers it the most activated, accessible, perhaps important throat in the discourse context" (Scott, 2013:63).

In summary, examples such as (32), (33) and (41) reveal that the procedures encoded by pronouns may contribute more than just a referent to the overall interpretation of an utterance. In this section I have focused on the contribution that they may make to the expressive effects of an utterance, and this in turn has consequences for how we view both expressive and procedural meaning. In the next section I show how a sub-personal analysis of examples like these lends support to Blakemore's characterisation of expressive meaning generally.

\subsection{Implications for expressive meaning}

Blakemore $(2011,2014)$ argues against a unitary account of expressive meaning. As she puts it, "the phenomena which have been claimed to exhibit this type of meaning do not form a natural class" (2011:3538). Rather expressive effects arise in a variety of cases. For example, she makes a general distinction between expressions such as damn which "activate procedures for the retrieval of emotional states" (2014:7), and epithets such as bastard, which "achieve their expressive effects via the encyclopaedic assumptions associated with the concepts they are understood to communicate" (2013:33). Pronouns, however, fall into neither of these classes. They can be used simply to guide reference resolution and, unlike damn, do not necessarily give any indication of speaker attitude or emotion. I have also argued that we can better account for the data if we move away from the idea that they encode person-level concepts. Rather, the procedure they encode indicates how the speaker sub-personally categorises representations of the intended referents. In some cases this will guide reference resolution, but in others it may achieve relevance by indicating the speaker's attitude or emotions. In this respect, the expressive effects associated with some uses of pronouns are closer to those arising from repetitions, such as in (43), discussed in Blakemore (2011):

My childhood days are gone, gone (from Sperber and Wilson, 1986/95:221).

As Blakemore notes, the effects of repetition are worked out differently in different utterances, and so "the search for a specific rule relating to repetition and its effects would be fruitless" (2011:3547). Rather, the effects that arise are context specific and driven by the hearer's search for relevance. As Sperber and Wilson explain, the hearer must "reconcile the fact that a certain expression has been repeated with the fact that optimal relevance has been aimed at" (1986/95:220). The same pattern applies to the marked uses of pronouns that we see in examples such as (33). It is not the use of it per se that results in expressive effects, but the cognitive procedure that use of it triggers in that particular discourse context. Thus, while use of an apparently inappropriate pronoun leads to the communication of negative, dissociative effects in (33), it can lead to different expressive effects in different utterances. For example, speakers may use first person pronouns to associate themselves with somebody or something. Consider the example in (44):

Twelve days ago we were drawing nil-nil with West Ham. Now we're top of the league. ${ }^{8}$

Uttered by a supporter of Chelsea Football Club, (44) is fairly typical of utterances produced by sports fans referring to the team they support. While the speaker does not play for the football team and took no active part in the events that are described, he uses the pronoun we to refer to the team. The sports club, its players and other fans all fall, for him, within the

\footnotetext{
${ }^{8}$ From The Chels Podcast (Daniels et al., 2014).
} 
set of things that can be referred to as we in this discourse context. It is difficult to pin down in conceptual terms precisely what the use of we communicates in this utterance, but it indicates some sort of allegiance, camaraderie, and shared values and outlook. The use of we rather than they does not affect the proposition expressed by the utterance. However, the fact that the speaker of (44) represents both the footballers in the Chelsea team and himself as falling within the same sub-personally identifiable category reveals his attitude and emotion towards that referent.

Whereas it may be possible to argue that interjections such as damn or expressive epithets such as the bastard might form some sort of natural class of expressives, the fact that, like repetition, pronoun choice can communicate expressive effects, supports Blakemore's case against a unitary account of expressives. As she explains, "their expressive interpretation will depend on whether or not the point of the utterance containing them is understood to lie in the expression of the speaker's attitude or emotions" (2013:3). The procedures encoded by the pronouns interact with the discourse context to guide the hearer to an optimally relevant overall interpretation.

\section{Concluding remarks: the nature of procedural meaning}

When she first formulated the notion of procedural meaning, Blakemore raised the hypothesis that there are, "expressions which systematically correspond to sub-personal computations" (2011:3540), and which contribute to relevance by "triggering mental processes" (2011:3541). I have suggested that use of a particular pronoun reveals how a speaker categorises the intended referent, or how she thinks her hearer might categorise it. My account moves away from the existing personal level explanations in which a pronoun instructs the hearer to look for a particular quality or feature in the referent (such as gender or number) or to look for a referent which has a particular level of activation (Accessibility or cognitive status) at that particular moment. Instead, the categorisation operates at a sub-personal level. As Dennett (1969:92) puts it "[w]hen one is asked how one tells an $x$ from a $y$ and answers that $x$ 's have an indefinable characteristic which one is simply able to recognise but not describe, all one is saying is: I can tell - that's all'. Hearers are able to recognise referents that are appropriately referred to by use of a particular pronoun in a particular discourse context. Once the set of potential referents has been narrowed to those belonging to that category, the hearer will follow the relevance theoretic comprehension procedure and test interpretations in order of accessibility. In cases where the intended referent has been made highly accessible by other means, a speaker may use the choice of referring expression to achieve expressive effects. By associating the intended referent with a particular sub-personal category, the speaker can reveal her attitudes and emotions towards the referent, as well as guiding the reference resolution process itself.

\section{Acknowledgements}

I would like to thank Diane Blakemore for her help, support and generosity. Her ideas on procedural meaning and expressives have informed and inspired my work, and I am extremely grateful both for the encouragement and for the insightful discussions. Thanks also go to Deirdre Wilson for her comments on earlier versions of this paper, and to three anonymous reviewers for their time and ideas.

\section{References}

Agar, N., 1993. What do frogs really believe? Australas. J. Philos. 71 (1), 1-12.

Ariel, M., 1988. Referring and accessibility. J. Linguist. 24 (1), 65-87.

Ariel, M., 1990. Accessing Noun Phrase Antecedents. Routledge, London.

Ariel, M., 1991. The function of accessibility in a theory of grammar. J. Pragmat. 16, 443-463.

Ariel, M., 1994. Interpreting anaphoric expressions: a cognitive versus a pragmatic approach. J. Linguist. 30 (1), 3-42.

Ariel, M., 2001. Accessibility theory: an overview. In: Sanders, T., Schliperoord, J., Spooren, W. (Eds.), Text Representation: Linguistic and Psycholinguistic Aspects. John Benjamins, Amsterdam, pp. 29-87.

Blakemore, D., 1987. Semantic Constraints on Relevance. Blackwell, Oxford.

Blakemore, D., 1992. Understanding Utterances. Blackwell, Oxford.

Blakemore, D., 2000. Indicators and procedures: nevertheless and but. J. Linguist. 36 (3), 463-486.

Blakemore, D., 2002. Relevance and Linguistic Meaning: The Semantics and Pragmatics of Discourse Markers. Cambridge University Press, Cambridge.

Blakemore, D., 2007. Constraints, concepts and procedural encoding. In: Burton-Roberts, N. (Ed.), Pragmatics. Palgrave MacMillan, Basingstoke, pp. 45-66.

Blakemore, D., 2011. On the descriptive ineffability of expressive meaning. J. Pragmat. 43, 3537-3550.

Blakemore, D., 2013. The Expressive Meaning of Racial Epithets: Towards a Non-unitary Account of Expressive Meaning. Faculty of Arts Scholarly and Research Events, 11 December. University of Brighton, Brighton.

Blakemore, D., 2014. Slurs and expletives: a case against a general account of expressive meaning. Lang. Sci.. http://dx.doi.org/10.1016/j. langsci.2014.06.018

Borthen, K., 2008. Descriptive content as higher-level explicatures NTNU Working Papers 5, pp. 67-79. 
Borthen, K., Bröseth, H., 2010. The procedural and conceptual meaning of they. In: Walaszewska, E., Kisielewska-Krysiuk, M., Piskorska, A. (Eds.), In the Mind and across Minds. Cambridge Scholars Publishing, Newcastle upon Tyne, pp. 86-96.

Borthen, K., Thomassen, G., 2014. Referential and functional aspects of the Norwegian first person plural vi. In: 'We' Across Languages and Contexts. John Benjamins, Amsterdam, pp. 65-82.

Bullokar, W., 1586. Pamphlet for Grammar. Edmund Bollifant, London.

Carston, R., 1999. The relationship between generative grammar and (relevance theoretic) pragmatics. UCL Working Pap. Linguist. 11, 21-40.

Carston, R., 2002a. Thoughts and Utterances: The Pragmatics of Explicit Communication. Blackwell, Oxford.

Carston, R., 2002b. Linguistic meaning, communicated meaning and cognitive pragmatics. Mind Lang. 17, $127-148$.

Clark, B., 2013. Relevance Theory. Cambridge University Press, Cambridge.

Daniels, P., Levy, C., Young, J., 2014. 'Mind Games' [Podcast]. Available at: http://www.chelseapodcast.net (accessed 09.07.15)

Demme, J., 1991. The Silence of the Lambs. [Motion Picture].

Dennett, D.C., 1969. Content and Consciousness. Routledge and Kegan Paul, London.

Drag Queens of London, 2014. London Live. 22nd April.

Fodor, J., 1975. The Language of Thought. Harvard University Press, Cambridge, MA.

Fodor, J., 2008. LOT2: The Language of Thought Revisited. Oxford University Press, Oxford.

Gundel, J.K., 2003. Information Structure and Referential Givenness/Newness: How much Belongs in the Grammar? CSLI Publications, Michigan.

Gundel, J.K., 2010. Reference and Accessibility from a Givenness Hierarchy Perspective. Int. Rev. Pragmat. 2 (2), $148-168$.

Gundel, J.K., Mulkern, A.E., 1998. Quantity implicatures in reference understanding. Pragmat. Cogn. 6 (1/2), 21-45.

Gundel, J.K., Hedberg, N., Zacharski, R., 1993. Cognitive status and the form of referring expressions in discourse. Language 69 (2), 274-307.

Hall, A., 2007. Do discourse markers encode concepts or procedures? Lingua 111 (1), 149-174.

Hedley, P., 2005. Pronouns, procedures and relevance theory. Durham Working Pap. Linguist. 11, 41-55.

Hedley, P., 2007. Anaphora, Relevance and the Conceptual/Procedural Distinction (DPhil thesis). Magdalen College, Oxford.

Iten, C., 2005. Linguistic Meaning, Truth Conditions and Relevance: the Case of Concessives. Palgrave MacMillan, Basingstoke.

Jespersen, O., 1940. A Modern English Grammar Part V. Munksgaard, Copenhagen.

Kaplan, D., 1989. Themes from Kaplan. Oxford University Press, Oxford.

Katz, J., Postal, P.M., 1964. An Integrated Theory of Linguistic Descriptions. MIT Press, Cambridge, MA.

Lettvin, J.Y., Maturana, H.R., McCulloch, W.S., Pitts, W.H., 1959. What the frog's eye tells the frog's brain. Proc. IRE 47, $1940-1951$.

Matsui, T., 2000. Bridging and Relevance. John Benjamins, Amsterdam.

Neale, S., 2007. Heavy hands magic, and scene-reading traps. Eur. J. Anal. Philos. 3 (2), 77-132.

Powell, G., 2002. Reference and Relevance (PhD thesis). University College London.

Powell, G., 2010. Language, Thought and Reference. Palgrave MacMillan, Hampshire.

Savage, D., 2014, June. Is Truvada for HIV Prevention a Good Idea [Podcast]. Available at: http://www.savagelovecast.com/episodes/398\#. U6hK87F9IUi (accessed 23.06.14)

Schmerling, S., 1982. How imperatives are special, and how they aren’t. In: Schneider, R., Tuite, K., Chametzky, R. (Eds.), Chicago Linguistic Society: Parasession on Nondeclaratives, pp. 202-218.

Scott, K., 2013. This and that: a procedural analysis. Lingua 131, 49-65.

Sperber, D., 1994. Understanding verbal understanding. In: Khalfa, J. (Ed.), What is Intelligence? Cambridge University Press, Cambridge, pp. 179-198.

Sperber, D., Wilson, D., 1986/95. Relevance: Communciation and Cognition. Blackwell, Oxford.

Sperber, D., Wilson, D., 2002. Pragmatics, modularity and mind-reading. Mind Lang. 17 (1), 3-23.

Sweet, H., 1960. New English Grammar. Oxford University Press, London.

Thorne, J.P., 1966. English imperative sentences. J. Linguist. 2 (1), 69-78.

Wharton, T., 2003. Interjections, language, and the showing/saying continuum. Pragmat. Cogn. 11 (1), 39-91.

Wilson, D., 1992. Reference and relevance. UCL Working Pap. Linguist. 4, 167-191.

Wilson, D., 2011. The conceptual-procedural distinction: past, present and future. In: Escandell-Vidal, V., Leonetti, M., Ahern, A. (Eds.),

Procedural Meaning: Problems and Perspectives, vol. 25. Emerald, Bingley, pp. 3-31.

Wilson, D., Sperber, D., 1993. Linguistic form and relevance. Lingua 90, 1-25.

Wilson, D., Sperber, D., 2004. Relevance theory. In: Horn, L.R., Ward, G.G. (Eds.), The Handbook of Pragmatics. Blackwell, Oxford, pp. 607-632.

Wilson, D., Sperber, D., 2012. Meaning and Relevance. Cambridge University Press, Cambridge.

Wilson, D., Wharton, T., 2006. Relevance and prosody. J. Pragmat. 38 (10), 1559-1579. 